\title{
Palpebral Involvement as a Presenting and Sole Manifestation of Discoid Lupus Erythematosus
}

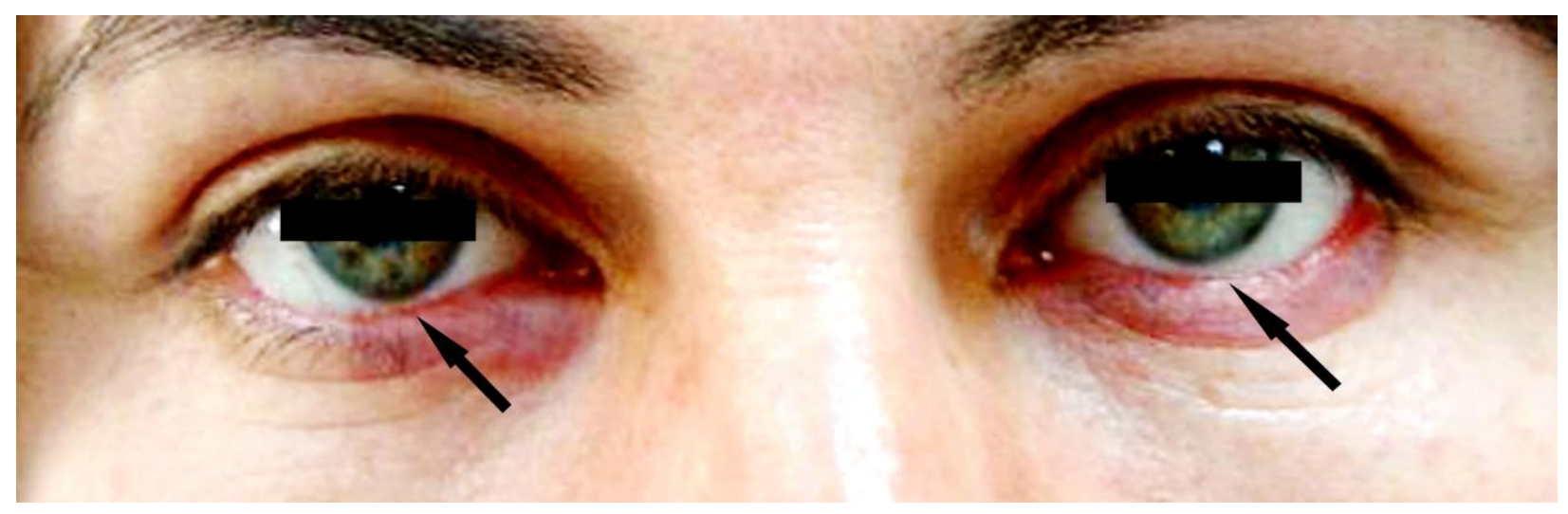

FIGURE 1. Edematous, erythematous plaques of the lower eyelids with madarosis (arrows).

Reza Yaghoobi ${ }^{1}$, Amir Feily ${ }^{1, *}$, Bahar Behrooz ${ }^{1}$, Elena Yaghoobi, and Shabnam Mokhtarzadeh ${ }^{2}$

${ }^{1}$ Department of Dermatology, Jundishapur University of Medical Sciences, Ahvaz, Iran; ${ }^{2}$ Department of Dermatological Sciences, University of Florence, Italy

E-mail: Yaghoobi rz@yahoo.com; dr.feily@yahoo.com; bahar 61558@yahoo.com; elenayaghoobi@yahoo.com; shabmz@yahoo.it

Received August 27, 2010; Revised October 13, 2010; Accepted October 14, 2010; Published November 4, 2010

KEYWORDS: DLE, palpebral involvement

A 28-year-old woman presented with a 2-year history of idiopathic, chronic blepharitis unresponsive to several courses treatment of corticosteroid eye drops. Physical examination was notable for edematous, erythematous plaques of the lower eyelids with madarosis in the absence of preceding skin scarring (Fig. 1). Biopsy specimen was obtained and diagnosis of discoid lupus erythematosus (DLE) was made. DLE is a chronic, cutaneous disease that is clinically characterized by a malar rash, acute erythema, and discoid lesions[1]. Localized DLE occurs when the head and neck only are affected, while widespread DLE occurs when other areas are affected, regardless of whether disease of the head and neck is seen[2,3,4,5,6]. Patients with widespread involvement often have hematologic and serologic abnormalities, are more likely to develop systemic lupus erythematosus, and are more difficult to treat[7]. A number of skin diseases may be confused with DLE, such as psoriasis, seborrheic dermatitis, acne, 
rosacea, lupus vulgaris, sarcoidosis, Bowen's disease, polymorphous light eruption, lichen planopilaris[8], dermatomyositis[9], granuloma annulare[10], and granuloma faciale[11]. Palpebral lesions may rarely be the presenting or sole manifestation of the disease[12] and lower eyelid involvement is seen in $6 \%$ of patients with chronic, cutaneous lupus erythematosus[1]. DLE should therefore be considered as a differential diagnosis in chronic blepharitis or madarosis that persists despite usual medical management and eyelid hygiene[12]. The patient was treated successfully with hydroxychloroquine. The skin lesions resolved with minimal scarring.

\section{REFERENCES}

1. Pianigiani, E., Andreassi, A., De Aloe, G., Rubegni, P., Rufa, A., and Motolese, E. (2002) Chronic erythematous desquamative plaques of the eyelids: discoid lupus erythematosis (DLE). Arch. Dermatol. 138(4), 527-532.

2. Uy, H.S., Pineda, R., 2nd, Shore, J.W., Polcharoen, W., Jakobiec, F.A., and Foster, C.S. (1999) Hypertrophic discoid lupus erythematosus of the conjunctiva. Am. J. Ophthalmol. 127(5), 604-605.

3. Acharya, N., Pineda, R., 2nd, Uy, H.S., and Foster, C.S. (2005) Discoid lupus erythematosus masquerading as chronic blepharoconjunctivitis. Ophthalmology 112(5), e19-23.

4. Gloor, P., Kim, M., McNiff, J.M., and Wolfley, D. (1997) Discoid lupus erythematosus presenting as asymmetric posterior blepharitis. Am. J. Ophthalmol. 124(5), 707-709.

5. Ena, P., Pinna, A., and Carta, F. (2006) Discoid lupus erythematosus of the eyelids associated with staphylococcal blepharitis and Meibomian gland dysfunction. Clin. Exp. Dermatol. 31(1), 77-79.

6. Huey, C., Jakobiec, F.A., Iwamoto, T., Kennedy, R., Farmer, E.R., and Green, W.R. (1983) Discoid lupus erythematosus of the eyelids. Ophthalmology $\mathbf{9 0 ( 1 2 ) , 1 3 8 9 - 1 3 9 8 .}$

7. Frith, P., Burge, S.M., Millard, P.R., and Wojnarowska, F. (1990) External ocular findings in lupus erythematosus: a clinical and immunopathological study. Br. J. Ophthalmol. 74(3), 163-167.

8. http://www.wrongdiagnosis.com/d/discoid_lupus_erythematosus/misdiag.htm (last accessed on October 13, 2010)

9. $\quad$ http://emedicine.medscape.com/article/1064945-overview (last accessed on October 7, 2010)

10. http://emedicine.medscape.com/article/1123031-overview (last accessed on October 7, 2010)

11. http://emedicine.medscape.com/article/1083474-overview (last accessed on October 7, 2010)

12. Selva, D., Chen, C.S., James, C.L., and Huilgol, S.C. (2003) Discoid lupus erythematosus presenting as madarosis. Am. J. Ophthalmol. 136(3), 545-546.

\section{This article should be cited as follows:}

Yaghoobi, R., Feily, A., Behrooz, B., Yaghoobi, E., and Mokhtarzadeh, S. (2010) Palpebral involvement as a presenting and sole manifestation of discoid lupus erythematosus. TheScientificWorldJOURNAL 10, 2130-2131. DOI 10.1100/tsw.2010.209. 


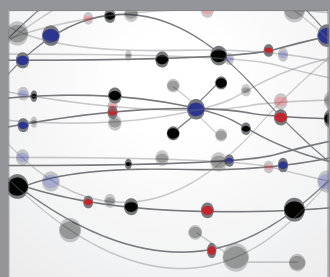

The Scientific World Journal
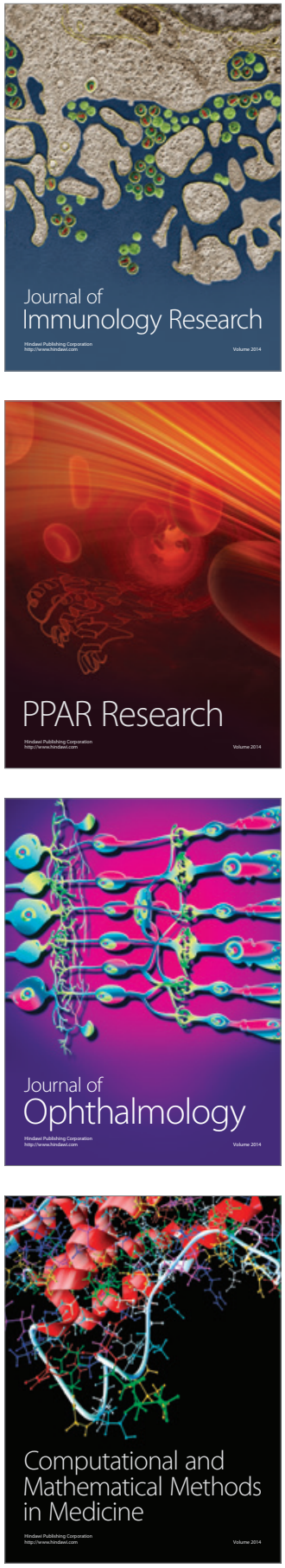

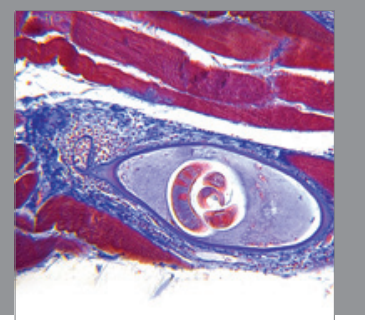

Gastroenterology

Research and Practice
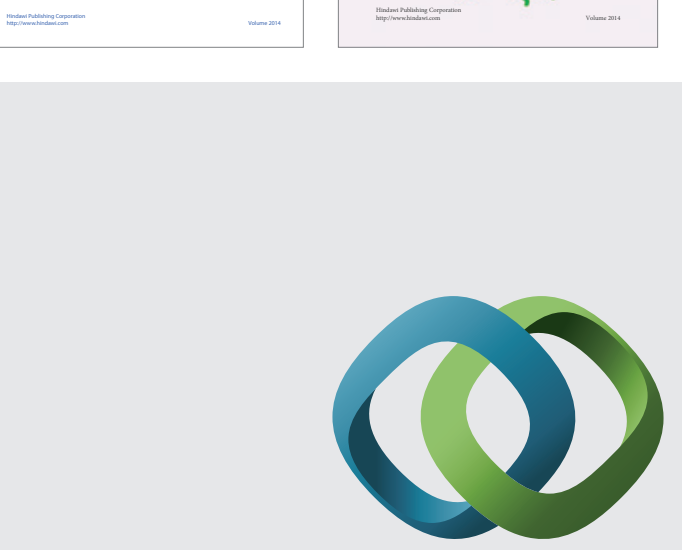

\section{Hindawi}

Submit your manuscripts at

http://www.hindawi.com
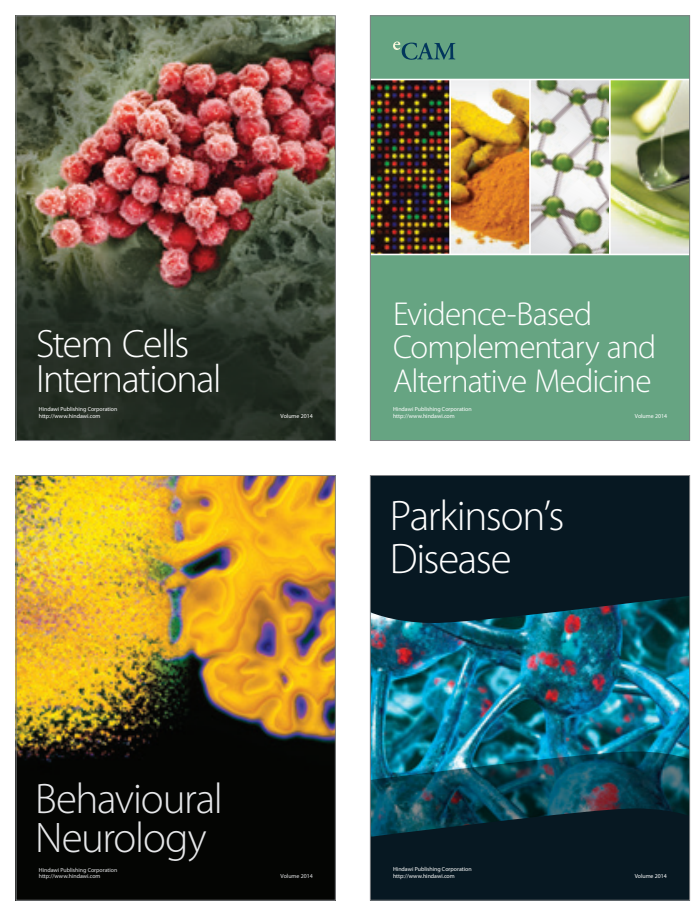

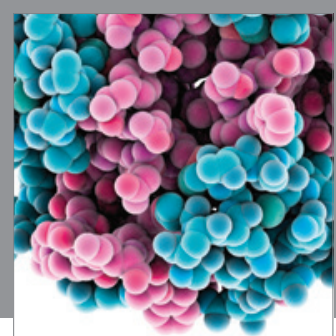

Journal of
Diabetes Research

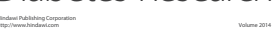

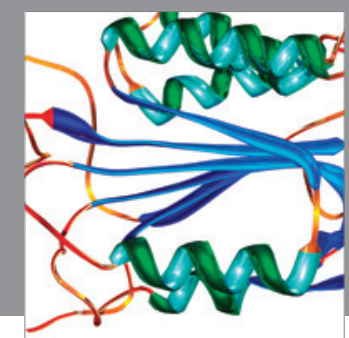

Disease Markers
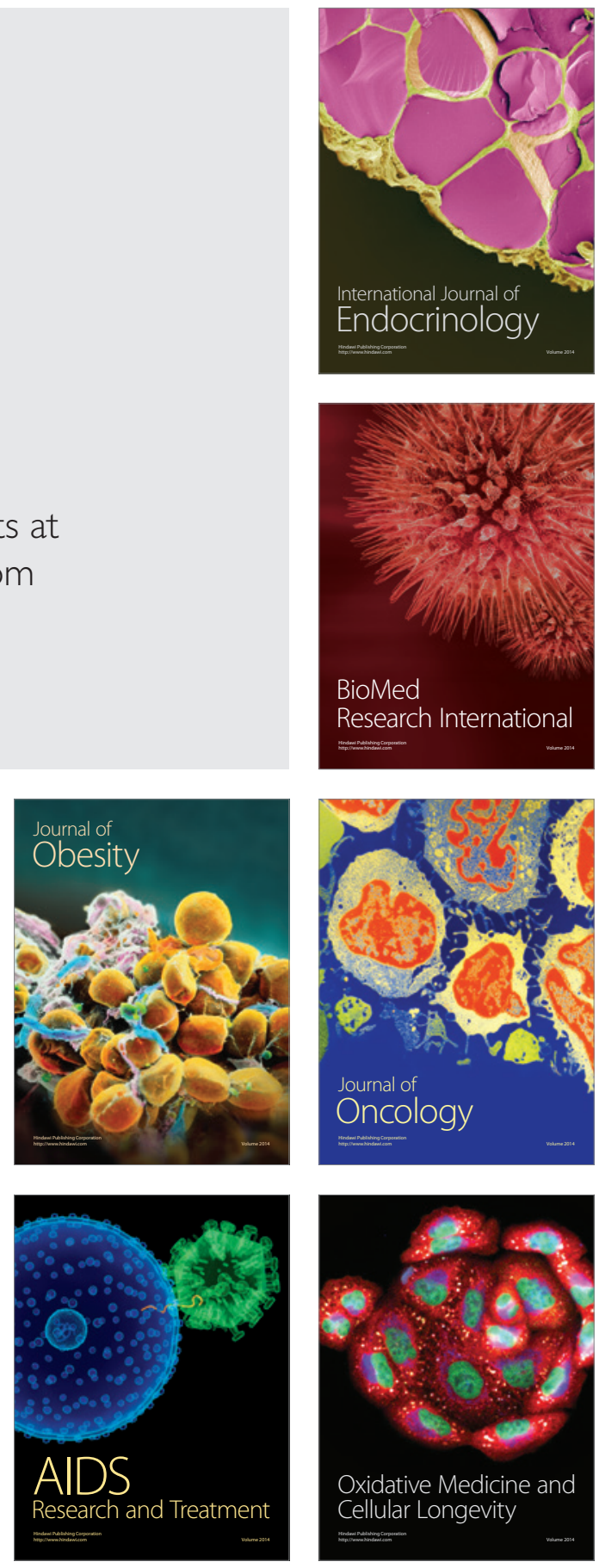